\title{
A multicenter randomized clinical trial investigating the cost-effectiveness of treatment strategies with or without antibiotics for uncomplicated acute diverticulitis (DIABOLO trial)
}

Çağdaş Ünlü ${ }^{1,2^{*}}$, Niels de Korte ${ }^{3}$, Lidewine Daniels², Esther CJ Consten ${ }^{4}$, Miguel A Cuesta $^{5}$, Michael F Gerhards ${ }^{6}$, Anna AW van Geloven ${ }^{7}$, Edwin S van der Zaag ${ }^{8}$, Joost AB van der Hoeven ${ }^{9}$, Rutger Klicks ${ }^{10}$, Huib A Cense ${ }^{11}$, Rudi MH Roumen ${ }^{12}$, Quirijn AJ Eijsbouts ${ }^{13}$, Johan F Lange ${ }^{14}$, Paul Fockens ${ }^{15}$, Corianne AJM de Borgie ${ }^{16}$, Wilem A Bemelman², Johannes B Reitsma ${ }^{16}$, Hein BAC Stockmann³, Bart C Vrouenraets', Marja A Boermeester ${ }^{2}$, Dutch Diverticular Disease (3D) Collaborative Study Group

\begin{abstract}
Background: Conservative treatment of uncomplicated or mild diverticulitis usually includes antibiotic therapy. It is, however, uncertain whether patients with acute diverticulitis indeed benefit from antibiotics. In most guidelines issued by professional organizations antibiotics are considered mandatory in the treatment of mild diverticulitis. This advice lacks evidence and is merely based on experts' opinion. Adverse effects of the use of antibiotics are well known, including allergic reactions, development of bacterial resistance to antibiotics and other side-effects.
\end{abstract}

Methods: A randomized multicenter pragmatic clinical trial comparing two treatment strategies for uncomplicated acute diverticulitis. I) A conservative strategy with antibiotics: hospital admission, supportive measures and at least 48 hours of intravenous antibiotics which subsequently are switched to oral, if tolerated (for a total duration of antibiotic treatment of 10 days). II) A liberal strategy without antibiotics: admission only if needed on clinical grounds, supportive measures only. Patients are eligible for inclusion if they have a diagnosis of acute uncomplicated diverticulitis as demonstrated by radiological imaging. Only patients with stages $1 \mathrm{a}$ and $1 \mathrm{~b}$ according to Hinchey's classification or "mild" diverticulitis according to the Ambrosetti criteria are included. The primary endpoint is time-to-full recovery within a 6-month follow-up period. Full recovery is defined as being discharged from the hospital, with a return to pre-illness activities, and VAS score below 4 without the use of daily pain medication. Secondary endpoints are proportion of patients who develop complicated diverticulitis requiring surgery or non-surgical intervention, morbidity, costs, health-related quality of life, readmission rate and acute diverticulitis recurrence rate. In a non-inferiority design 264 patients are needed in each study arm to detect a difference in time-to-full recovery of 5 days or more with a power of $85 \%$ and a confidence level of $95 \%$. With an estimated one percent of patients lost to follow up, a total of 533 patients will be included.

Conclusion: A clinically relevant difference of more than 5 days in time-to-full recovery between the two treatment strategies is not expected. The liberal strategy without antibiotics and without the strict requirement for hospital admission is anticipated to be more a more cost-effective approach.

Trial registration: Trial registration number: NCT01111253

\footnotetext{
* Correspondence: c.unlu@amc.uva.nl

${ }^{1}$ Department of Surgery, Sint Lucas Andreas Hospital Amsterdam, the Netherlands
} 


\section{Background}

Prevalence of diverticular disease increases with age, from less than $10 \%$ in people younger than age 40 to $50-66 \%$ in octogenarians, with similar frequency in men and women. Approximately three quarters of patients with diverticulosis remain asymptomatic throughout their lifetime. Asymptomatic disease is often an incidental finding during imaging or endoscopy for suspicion of colonic disorders. Of the $25 \%$ of patients who develop symptomatic diverticular disease, approximately three quarters develop diverticulitis [1,2]. Of all patients with diverticulitis, $75 \%$ have mild acute disease only and $25 \%$ develop complicated disease [3]. All and all about 5\% of patients with diverticulosis will undergo an episode of complicated diverticulitis.

The cause of colonic diverticular disease has not yet been conclusively established. Epidemiologic studies have demonstrated associations between diverticulosis and diets that are low in dietary fiber and high in refined carbohydrates. Low intake of dietary fiber results in less bulky stools retaining less water and altering gastrointestinal transit time. These factors could increase intracolonic pressure (development of pressure zones that create diverticula alongside the vasa recta), and make evacuation of colonic contents more difficult [4]. Other factors that have been associated with an increased risk of diverticular disease include physical inactivity, constipation, obesity, smoking, and treatment with non-steroidal anti-inflammatory drugs $[5,6]$.

Although much has been learned about the development of diverticula, less is known about the pathogenesis of diverticular inflammation. As discussed earlier, a minority of patients with diverticulosis will develop symptomatic disease. Initial theories of diverticulitis focused on ideas about the pathogenesis of appendicitis; a diverticulum lumen becomes obstructed by a faecolith leading to increased intradiverticular pressure and eventually causing inflammation. Interest has been generated in the role of altered peridiverticular colonic flora and low-grade chronic inflammation leading to periods of symptomatic disease, similar to periods of exacerbation and remission in inflammatory bowel disease [7].

The classical clinical presentation of diverticulitis in the western world includes left lower quadrant abdominal pain, tenderness, low-grade fever and leucocytosis. However, clinical features can be quite variable. Leucocytosis may only be present in $45-65 \%$ of the patients, and lowgrade fever may be present in only $21 \%$ [8].

For a reliable diagnosis additional imaging is usually necessary. Computed tomography (CT) is recommended as initial radiological examination. Positive findings in ultrasound (US) are equally accurate in the diagnosis of diverticulitis. However CT has an advantage in excluding alternative diagnoses and visualising complications of acute diverticulitis needing intervention. For both US and CT, sensitivity is as high as $90 \%$, with a specificity of up to 99\% for CT [9].

The severity of diverticulitis is often graded with the use of modified Hinchey's criteria, based on CT imaging and on preoperative findings $[10,11]$. The Ambrosetti's criteria is based only on CT imaging, classifying in "mild" and "severe" diverticulitis. This classification system does not take into account the effects of coexisting conditions on disease severity or outcome [12]. (Table 1) Stage II disease is related to a large $(>5 \mathrm{~cm})$ collection of pus, which is at distance (in the pelvis or the abdomen) of the sigmoid colon [10]. Stage II usually requires percutaneous drainage, while stages III and IV diverticulitis usually request surgery.

Conservative treatment of mild diverticulitis usually includes careful observation, restriction of oral intake, administration of intravenous fluids, and most patients receive antibiotic therapy. The majority of patients with mild diverticulitis improve with these conservative measures. Less than $10 \%$ need percutaneous or operative treatment for disease progression and/or complications [13,14].

It is, however, uncertain whether patients with acute diverticulitis benefit from antibiotics, since evidence from prospective studies or randomized trials is lacking. In a recent review antibiotics are considered mandatory in the treatment of mild diverticulitis [15]. This advice lacks evidence and is based on experts' opinion only. Anaerobes are commonly isolated organisms in acute diverticulitis. Gram-negative aerobes, especially Escherichia coli, and facultative gram-positive bacteria, such as streptococci, are often cultured as well [16]. Therefore, broad-spectrum antibiotics are advised. Which antibiotic regimen should be used in diverticulitis is unclear $[17,18]$. There is scarse evidence that oral antibiotics are as effective as intravenous antibiotics [19].

Only one study has investigated the use of antibiotics in the treatment of acute uncomplicated diverticulitis. In a retrospective study by Hjern et al [20], there was no significant benefit from antibiotics in the treatment of mild diverticulitis. However, this study was hampered by selection bias due to its retrospective design and small patient groups.

Moreover, there is major discrepancy in the use of antibiotics between countries in Northwest Europe and other countries, including the United States and United Kingdom. In the Netherlands and Scandinavian countries antibiotic use for this disease is less common compared to these other countries, where antibiotics are considered mandatory. A Dutch survey showed that many gastro-enterologists prescribed antibiotics in the treatment of acute diverticulitis, but only a minority of 
Table 1 Hinchey classification and modified Hinchey classification of acute diverticulitis [10,12]

\begin{tabular}{ll}
\hline Hinchey & Modified Hinchey \\
\hline I Pericolic abscess or phlegmon & 0 Mild clinical diverticulitis \\
\hline II Pelvic, intraabdominal, or retroperitoneal abscess & 1a Colonic wall thickening/Confined pericoloc inflammation \\
\cline { 2 - 2 } III Generalized purulent peritonitis & Ib Confined small $(<5 \mathrm{~cm})$ pericolic abscess \\
\hline IV Generalized fecal peritonitis & II Pelvic, distant intraabdominal, or retroperitoneal abscess \\
\hline
\end{tabular}

Dutch surgeons did so [21]. In contrast, all UK surgeons responding to a survey prescribed antibiotics in the initial treatment of diverticulitis and $43 \%$ of them even for 7 days after hospital discharge [22].

Six professional organisations have issued formal guidelines concerning the use of antibiotics in uncomplicated diverticulitis. Five of these guidelines advice the use of antibiotics. (Table 2) [23-28]. Patients should start with intravenous antibiotics and after improvement within 2-4 days, oral antibiotics are continued to complete a 7-10 days treatment regimen. In the Netherlands, the Dutch Antibiotic Policy Committee considers antibiotics not primarily indicated in the treatment of uncomplicated diverticulitis [28].

Adverse effects of antibiotics are well known, such as allergic reactions and development of antibiotic resistance of bacterial species. The frequency of toxicodermia is $7-8 \%$ with the use amoxicillin, allergy reactions are accounted for in $1 \%$ of the patients, and the incidence of anaphylactic shock is $0,01-0,04 \%$ with the use of penicillin. Therefore, efforts are made to minimize the use of antibiotics in various fields in clinical medicine [29].
The lack of evidence for its use necessitates a scientific judgement of the role of antibiotics in the treatment of uncomplicated diverticulitis. Therefore, we initiated a randomized multicenter trial to investigate the effect of antibiotics on disease course in patients with mild acute diverticulitis.

\section{Methods/Design \\ Objective}

The main goal of the present study is to establish whether antibiotics are necessary in the primary treatment of acute mild diverticulitis, and whether a more liberal strategy without initial antibiotics is more costeffective with respect to time-to-full recovery.

In daily practice there is an ongoing discussion about the relative benefits and disadvantages of a more conservative treatment strategy embracing the use of intravenous antibiotics. This strategy needs hospital admission and is, at least at the start, an in-hospital treatment regimen. A more liberal strategy, without antibiotics and without the strict requirement of hospital admission, may lead to a shorter hospital stay and reduced costs without compromising outcome.

Table 2 Published guidelines and practise parameters

\begin{tabular}{|c|c|c|c|c|c|c|c|}
\hline Organization & Year & $\begin{array}{l}\text { Antibiotics } \\
\text { Recommended }\end{array}$ & $\begin{array}{l}\text { Original } \\
\text { research } \\
\text { cited }\end{array}$ & $\begin{array}{l}\text { Which } \\
\text { antibiotics }\end{array}$ & $\begin{array}{l}\text { Original } \\
\text { research } \\
\text { cited }\end{array}$ & Route of administering & $\begin{array}{l}\text { Original } \\
\text { research } \\
\text { cited }\end{array}$ \\
\hline $\begin{array}{l}\text { American College of } \\
\text { Gastroenterology[23] }\end{array}$ & 1999 & Yes & None & $\begin{array}{l}\text { Covering both Gram } \\
\text { negative and } \\
\text { anaerobes }\end{array}$ & Kellum [15] & $\begin{array}{l}\text { Oral or intravenous, } \\
\text { depending on clinical } \\
\text { status }\end{array}$ & None \\
\hline $\begin{array}{l}\text { European Association for } \\
\text { Endoscopic Surgery[25] }\end{array}$ & 1999 & Yes & None & $\begin{array}{l}\text { Ciprofloxacin } \\
\text { And Metronidazol }\end{array}$ & None & $\begin{array}{l}\text { Oral or intravenous, } \\
\text { depending on clinical } \\
\text { status }\end{array}$ & None \\
\hline $\begin{array}{l}\text { American Society of Colon } \\
\text { and Rectal Surgeons[24] }\end{array}$ & 2006 & Yes & None & $\begin{array}{l}\text { Covering both Gram } \\
\text { negative and } \\
\text { anaerobes }\end{array}$ & Kellum [15] & $\begin{array}{l}\text { Oral or intravenous, } \\
\text { depending on clinical } \\
\text { status }\end{array}$ & None \\
\hline $\begin{array}{l}\text { Society of Surgery of the } \\
\text { Alimentary Tract[26] }\end{array}$ & 2007 & Yes & None & $\begin{array}{l}\text { Broad spectrum } \\
\text { antibiotics }\end{array}$ & None & $\begin{array}{l}\text { Oral or intravenous, } \\
\text { depending on clinical } \\
\text { status }\end{array}$ & None \\
\hline $\begin{array}{l}\text { World Gastroenterology } \\
\text { Organization[27] }\end{array}$ & 2007 & Yes & None & $\begin{array}{l}\text { Covering both Gram } \\
\text { negative and } \\
\text { anaerobes }\end{array}$ & None & $\begin{array}{l}\text { Oral or intravenous, } \\
\text { depending on clinical } \\
\text { status }\end{array}$ & None \\
\hline SWAB[28] & 2009 & $\begin{array}{l}\text { No, not } \\
\text { primarily }\end{array}$ & None & $\begin{array}{l}\text { Broad spectrum } \\
\text { antibiotics }\end{array}$ & None & $\begin{array}{l}\text { Oral or intravenous, } \\
\text { depending on clinical } \\
\text { status }\end{array}$ & None \\
\hline
\end{tabular}


Our hypothesis is that in uncomplicated (mild) acute diverticulitis, a liberal strategy treatment without antibiotics is a more cost-effective approach than conservative treatment strategy with hospital admission and antibiotics, outcome is measured by time-to-full recovery as primary outcome and diverticulitis-associated complication rates and patient well-being as secondary outcome.

\section{Study population}

Inclusion criteria:

1. Only left-sided and primary (first attack) mild acute diverticulitis.

2. Diagnosis of diverticulitis by US and conditional CT. Diverticulitis-positive US findings are sufficiently accurate compared to CT findings [9]. In diverticulitisnegative US findings in clinically suspected patients, immediate i.v. contrast-enhanced CT is mandatory for confirmation of diverticulitis and exclusion of other pathology.

3) Staging of diverticulitis by CT. CT is needed for all patients for Hinchey/Ambrosetti classification (which is a CT-based classification system). In diverticulitis-positive US findings CT has to be performed within 24 hours. Staging diverticulitis is defined according the modified Hinchey/Ambrosetti staging. Only modified Hinchey stages $1 \mathrm{a}$ and $1 \mathrm{~b}$ (1a Colonic wall thickening/ Confined pericolic inflammation, $1 \mathrm{~b}$ Confined small pericolic abscess) and Ambrosetti's "mild" diverticulitis stage are included. Figure 1 depicts a flow chart, showing the inclusion criteria and the steps after inclusion [10-12].

4. Informed consent.

Exclusion criteria are summarized in Table 3.

\section{Study outline}

Patients will be randomly allocated to one of the following two treatment strategies: Conservative strategy including immediate antibiotic treatment or liberal strategy without antibiotics (supportive measures only). (Table 4).

In the conservative strategy, the use of antibiotics will be intravenously for at least 48 hours after which route of administration can be switched to orally if tolerated. Hospital admission in the liberal strategy is needed for patients with nausea and vomiting, in need of intravenous fluids or for patients with excessive pain not properly reacting to oral pain medication.

The interval between start of symptoms of the patient and administration of antibiotics will be registered. Also the period after inclusion and the actual first administration of antibiotics will be registered.

In both strategies CT is repeated in case of clinical deterioration. For patients in the liberal strategy treatment arm, clinical deterioration and/or proven subsequent complicated diverticulitis and/or other infectious foci (e.g., pneumonia, infections) may dictate start of antibiotic treatment, instigated by the treating physician. Criteria to start antibiotics in the liberal arm are temperature $>39^{\circ} \mathrm{C}$, positive blood cultures and clinical suspicion of bacteraemia (i.e. sepsis). Criteria for sepsis are set by the American College of Chest Physicians and the Society of Critical Care Medicine. Two or more symptoms are required: Body temperature $\left\langle 36^{\circ} \mathrm{C}\right.$ or $>$ $38^{\circ} \mathrm{C}$, heart rate higher than 100 beats a minute, respiratory rate higher than 20 breaths a minute and white blood cell count $<4 \times 10^{9}$ or $>12 \times 10^{9}$ cells/L [31]. Also another infectious focus (e.g., pneumonia, urinary tract infections) may dictate start of antibiotic treatment, instigated by the treating physician.

The following discharge criteria are applied in both strategies: normal diet (defined by tolerating solid food and more than $1 \mathrm{~L}$ of fluid orally), temperature $<38.0^{\circ} \mathrm{C}$, VAS (Visual Analoge Score) pain score $<4$ (with paracetamol only), self support as compared to the pre-illness level, and acceptance by the patient.

All outpatients will daily monitor and register their body temperature. Written and oral instructions at discharge are given, and relevant telephone numbers and contact information will be provided. In case of fever above $38^{\circ} \mathrm{C}$, progression of pain above a VAS of 4 or other clinical signs of deterioration, patients can contact the hospital or emergency department immediately.

\section{Antibiotics}

For the choice and duration of antibiotics the practice guidelines of the Dutch Antibiotic Policy Committee [28] and the American Society of Colon and Rectal Surgeons [30] are followed. In both guidelines, a minimum of 7-14 days of broad-spectrum antibiotics is advised. In the present study amoxicillin-clavulanic acid is chosen as broad-spectrum antibiotic; duration of antibiotic treatment is 10 days. The dosage scheme for the study drug is $1200 \mathrm{mg}$ i.v. 4 times daily with subsequent oral administration of $625 \mathrm{mg} 3$ times daily. In case of allergy (known or newly diagnosed), a switch will be made to the combination of ciprofloxacine and metronidazole; ciprofloxacine 2 times a day $400 \mathrm{mg}$ i.v. and metronidazol 3 times daily $500 \mathrm{mg}$, with oral doses of ciprofloxacine being $500 \mathrm{mg} 2$ times a day and of metronidazol 3 times a day $500 \mathrm{mg}$.

\section{Endpoints}

The primary endpoint is time-to-full recovery within a follow-up period of 6 months. Full recovery is defined by the following criteria: discharged from the hospital (out-patient), normal diet (defined by tolerating solid food and more than 1L of fluid orally), temperature $<38.0^{\circ} \mathrm{C}$, and VAS pain score $<4$, no use of daily pain 


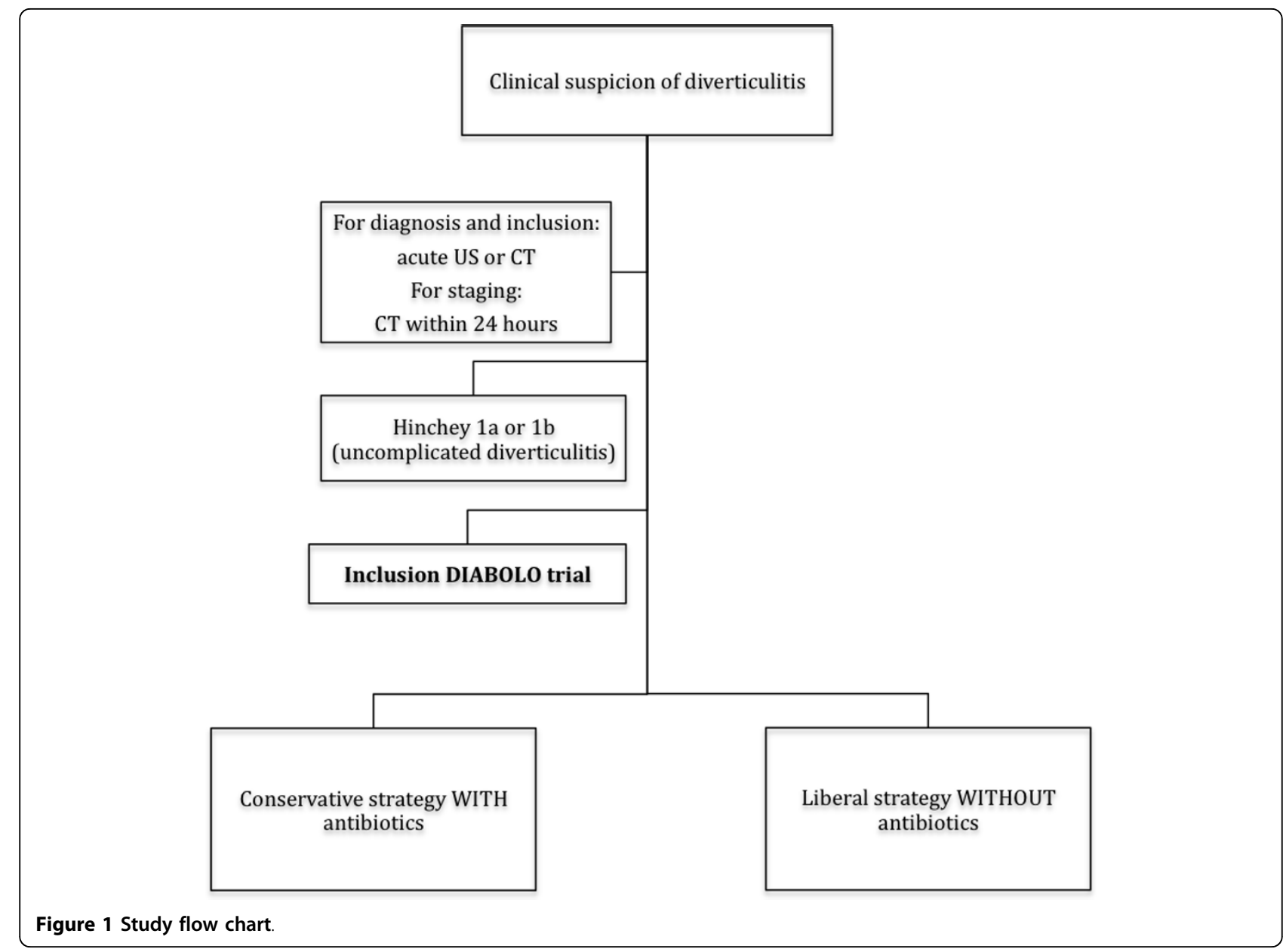

medication or back to pre-illness pain medication use, and resuming to pre-illness working activities; as assessed by questionnaires and out-patient clinic visits.

The secondary endpoints are: proportion of patients who develop complicated diverticulitis require surgery or non-surgical intervention; number of days outside the hospital in a 6 months period; direct and indirect medical costs at 6 months follow-up; occurrence of complicated diverticulitis defined as abscess, perforation, stricture and/or fistula; predefined side-effects of initial antibiotic treatment (e.g. antibiotic resistance/sensitivity pattern, allergy); morbidity (e.g. pneumonia, myocardial

Table 3 Exclusion criteria

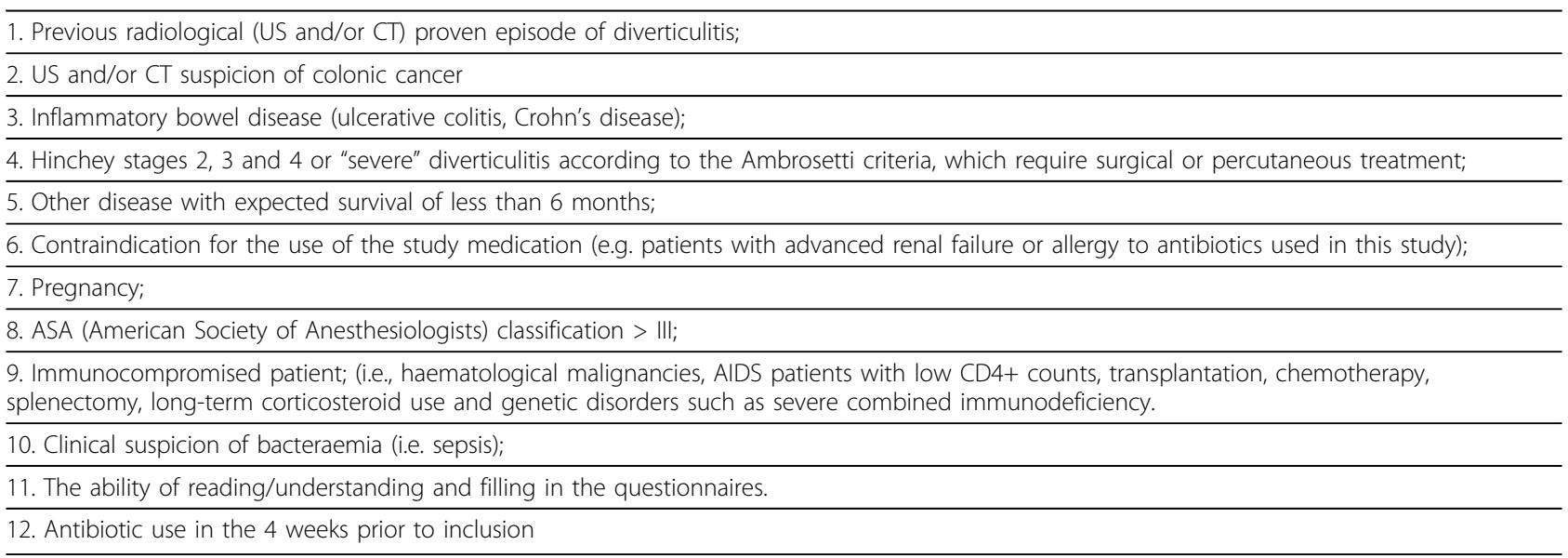


Table 4 Treatment strategies

\begin{tabular}{ll}
\hline Conservative strategy with antibiotics & $\begin{array}{l}\text { Liberal strategy without } \\
\text { antibiotics }\end{array}$ \\
\hline - Hospital admission; & $\begin{array}{l}\text { - Admission only if discharge criteria } \\
\text { are not met; }\end{array}$ \\
\hline - Intravenous fluids and at least 48 hours of intravenous antibiotics and subsequently switch to oral & - No initial antibiotics; \\
antibiotics if tolerated (otherwise continuation i.v.) to complete a full 10-day treatment duration; & - Adequate pain relief (VAS <4); \\
\hline - Adequate pain relief (VAS <4); & - Oral intake as tolerated; \\
\hline - Oral intake as tolerated; & - Daily monitoring when admitted to \\
\hline - Daily monitoring. & the hospital; \\
\hline -Self monitoring at home after discharge & - Self monitoring at home. \\
-Out patient follow-up at regular intervals & - Out patient follow-up at regular \\
\end{tabular}

infarction, urinary tract infection); mortality; readmission rate within 6 months and acute diverticulitis recurrence rates at 12 and 24 months follow-up. Changes in health status and valuation over time will be measured using generic and disease specific quality of life questionnaires (Euro-Qol 5D, Short Form 36 (SF-36) and the Gastro-Intestinal Quality of Life Index (Giqli)) on admission and after 3, 6, 12 and 24 months.

A recurrence is defined as ultrasound- or CT-proven acute diverticulitis after complete resolution of symptoms more than 1 month after initial discharge from hospital. If a patient dies during follow-up, the reason for death will be recorded as related or unrelated to diverticular disease.

\section{Randomization}

Computerized block randomization for allocation of treatment group, stratified for center and for Hinchey $1 \mathrm{a}$ and $1 \mathrm{~b}$, will take place after all inclusion and exclusion criteria have been verified and informed consent has been obtained. A standardized case record from (CRF) will be used. This CRF is partially web-based via a secured internet module. A minimum of $10 \%$ of the CRF data will be verified with source data by an independent audit.

\section{Sample size calculation and date analysis}

A non-inferiority design was chosen. Time-to-full recovery in the liberal strategy arm must not exceed a clinically relevant difference of more than 5 days compared with the conservative strategy. When this condition is fulfilled, the potential advantages of the liberal (nonantibiotic) strategy become dominant: patient well being when the need of hospital admission can be avoided, less costs, less antibiotic resistance and less other side effects. The study must have the power (superiority) to detect a difference in time-to-full recovery of 5 days.

The median time-to-full recovery is 21 days based on the National Dutch Hospital Registry data with an average of 7 days admission and an assumed additional median 14-day out-patient period to full recovery. To reject the null-hypothesis of a difference in time-to-full recovery of 5 days or less, using a time-to-event analysis with a power of $85 \%$ at a confidence level of $95 \%$, an accrual period of 730 days and a follow-up period of 180 days, at least 264 patients need to be included in each treatment arm. With an estimated one percent of the trial patients lost to follow-up, a total 533 patients is needed.

The primary endpoint is time-to-full recovery. KaplanMeier curves depicting the proportion of patients with full recovery since randomisation will be constructed for both strategies. The log rank test will be used to test for superiority of one strategy compared with the other. Testing for non-inferiority will be done by calculating the hazard ratio for the liberal strategy compared with the conservative strategy using Cox regression. We will calculate a one-sided 95\% confidence interval for this ratio to determine whether it reaches outside the hazard ratio belonging to an equivalence limit of a difference of 5 days in median survival time.

For other endpoints data will be compared by the Student's t test, Wilcoxon rank sum test, Chi square test or Fischer exact test as appropriate. In superiority tests a two-tailed $\mathrm{P}$ value $\leq 0.05$ will be considered statistically significant, whereas one-sided tests will be performed in non-inferiority testing. The main analyses will be based on the intention to treat principle. Predefined subgroup analyses to investigate whether treatment effects are different in subgroups will be performed for Hinchey classification $1 \mathrm{a}$ versus $1 \mathrm{~b}$ and for participating center.

\section{Cost analysis}

All related costs will be estimated based on the actual input terms of resource use and personnel in the 6-month follow-up period after randomization. For all cost-items such as hospital admission, medication used, diagnostic tests, unit costs will be derived from the 
Dutch costing manual or determined in cooperation with the hospital administration. Direct medical costs will be recorded in the case record forms. Indirect costs arising from losses in productivity will be assessed by means of the Health and Labor questionnaire and will be calculated by means of the friction cost method.

\section{Economic evaluation}

The economic evaluation will be performed from a societal perspective as a cost-effectiveness and cost-utility analysis. The main analyses include costs per day reduction to achieve full recovery and costs per QALY gained. Additional sensitivity analyses, regarding differences in possible subgroups, will be performed.

\section{Safety monitoring}

Adverse events are defined as any undesirable experience occurring to a subject during a clinical trial, whether or not considered related to the investigational drug. All adverse events reported spontaneously by the subject or observed by the investigator or his staff will be recorded. A serious adverse event (SAE) is any untoward medical occurrence or effect that at any dose results in death; is life threatening (at the time of the event); requires hospitalization or prolongation of existing inpatients' hospitalization; results in persistent or significant disability or incapacity; is a congenital anomaly or birth defect; is a new event of the trial likely to affect the safety of the subjects, such as an unexpected outcome of an adverse reaction, major safety finding from a newly completed animal study, etc. All SAEs will be reported to the accredited Medical Ethical Committee (MEC) that approved the protocol, according to the requirements of that MEC.

Suspected unexpected serious adverse reactions (SUSAR) are all untoward and unintended responses to an investigational product related to any dose administered.

Unexpected adverse reactions are adverse reactions, of which the nature, or severity, is not consistent with the applicable product information.

The sponsor will report expedited the following SUSARs to the MEC; SUSARs that have arisen in the clinical trial that was assessed by the MEC; SUSARs that have arisen in other clinical trial of the same sponsor and with the same medicinal product, and that could have consequences for the safety of the subjects involved in the clinical trial that was assessed by the MEC. The remaining SUSARs are recorded in an overview list (line-listing) that will be submitted once every half year to the MEC. This line listing provides an overview of all SUSARs from the study medicine, accompanied by a brief report highlighting the main points of concern.
The sponsor will report expedited all SUSARs to the competent authority, the Medicine Evaluation Board and the competent authorities in other Member States. The expedited reporting will occur not later than 15 days after the sponsor has first knowledge of the adverse reactions. For fatal or life threatening cases the term will be maximal 7 days for a preliminary report with another 8 days for completion of the report. There is no need to break any code in case of a SUSAR because due to the nature of the study in which neither participant nor treating physician are blinded.

In addition to the expedited reporting of SUSARs, the sponsor will submit, once a year throughout the clinical trial, a safety report to the accredited MEC, competent authority, Medicine Evaluation Board and competent authorities of the concerned Member States. This safety report consists of: a list of all suspected (unexpected or expected) serious adverse reactions, along with an aggregated summary table of all reported serious adverse reactions, ordered by organ system, per study; a report concerning the safety of the subjects, consisting of a complete safety analysis and an evaluation of the balance between the efficacy and the harmfulness of the medicine under investigation.

An independent data and safety monitoring committee will evaluate the progress of the trial and will examine safety parameters at regular intervals (every 25 patients). The committee can unblind the data whenever deemed necessary based on reported adverse events. All involved physicians will repetitively be asked to report any potential adverse events caused by the study protocol. These adverse events will be listed and discussed with the monitoring committee. The monitoring committee can ask for a full report in order to discuss a specific adverse event. A copy of this report will be send to the central ethics board and to the involved physicians. All deceased patients will be evaluated by the safety committee for cause of death and possible trial related serious adverse effects. Every death will be reported to the central ethics board and the local ethics board. The Data Safety Monitoring Board will consist of an epidemiologist/statistician who is the chairman, an independent surgeon and an independent radiologist.

\section{Ethics}

This study is conducted in accordance with the principles of the Declaration of Helsinki and 'good clinical practice' guidelines. The Medical Ethical Committee of the Academic Medical Center in Amsterdam has approved the protocol. The Ethical Committees of the participating centers is applied for local feasibility. Prior to randomization, written informed consent will be obtained from all patients. 


\section{Discussion}

Diverticular disease is the most common disease of the colon being found in every 1 of 3 people over the age of 60 years. The overall prevalence of diverticular disease during endoscopy is $27 \%$ [32]. A recent task force convened by the American Gastroenterological Association confirmed that diverticular disease is a major clinical problem. Diverticular disease is fifth in the list of digestive diseases in terms of total costs [33]. Hospital admission rates for colonic diverticulitis have increased in the last decades. In the United States the populationadjusted numbers of domestic admissions for acute diverticulitis increased by $26 \%$ [34].

Over the last decade there have been efforts made to minimize the prescription of antibiotics in various fields in clinical medicine. Patients with appendiceal inflammatory masses or acute cholecystitis are not treated primarily by antibiotics. This is also true for community-acquired infections, such as acute otitis media, upper respiratory tract infections and in paediatric medicine [35]. Bacterial resistance to antibiotics is a major public-health problem and antibiotic use is being increasingly recognized as the main selective pressure driving this resistance [36,37]. Development of Clostridium-associated diarrhea is however one of the downsides of antibiotic use, and subject of this study. With the use of beta-lactam antibiotics, infection with Clostridium difficile is a potential problem for all hospitalized patients. Clostridium difficile is implicated in $20-30 \%$ of patients with antibiotic-associated diarrhea, in $50-70 \%$ of those with antibiotic-associated colitis and in more than $90 \%$ of those with antibiotic-associated pseudomembranous colitis [38]. Alternatively, there is no evidence or guideline dictating that support anti-anaerobic prophylaxis for hospitalized patients in general. Prophylactic metronidazol to prevent Clostridium-associated diarrhea is not standard practice and is therefore not considered for this trial.

There are some new treatment options for symptomatic diverticular disease under investigation, such as mesalazin and probiotics. For the present randomized trial these treatments were not considered a reasonable alternative. First, these treatment options are not yet widely used and are only applied in the context of clinical trials. These studies have dealt with the treatment of uncomplicated symptomatic diverticular disease, and not with acute diverticulitis. Patients with proven diverticulosis and at least one months of symptoms had been included. These trials have excluded diverticulitis patients $[39,40]$. Some studies have assessed meselazin in the prevention of recurrent diverticulitis but never as the actual treatment of acute diverticulitis itself $[41,42]$. Third and foremost, the main topic in daily practice is whether antibiotics are mandatory in the treatment of acute diverticulitis. Until now, no randomized controlled trial has investigated this matter. Before other treatment options become an issue, first the efficacy of antibiotics in diverticulitis needs to be investigated, as this is currently standard practice in many countries.

In the present study we chose for a more pragmatic approach to investigate the effect of antibiotics in the treatment of acute uncomplicated diverticulitis. A clinical randomized trial setting was chosen over a doubleblind placebo controlled randomized trial. Our intention is to compare the contemporary treatment strategies in uncomplicated acute diverticulitis. In a pragmatic trial set-up the two possible treatment strategies can be investigated and the outcome will be more applicable in daily practice. In a double-blind placebo controlled trial the effect of antibiotics will be investigated in a more experimental setting were all patients will be admitted and the result will not be applicable to daily practice.

Not all patients with acute diverticulitis have to be admitted to the hospital. In 2005, Mizuki et al showed that outpatient treatment of patients with mild or uncomplicated diverticulitis is safe [43]. For this reason, in the present trial hospital admission is not mandatory in the liberal strategy arm when patients fulfill the 'discharge' criteria at time of study entry. Part of the conservative treatment is hospital admission and intravenous antibiotics as this is common practice. In both arms the same strict criteria for discharge apply.

We decided not to stratify for age, based on the prevalence of diverticulitis in the different age groups and on the latest literature on the outcome of diverticulitis. Diverticulitis occurs in $5-10 \%$ by the age of 40 years, in $10-30 \%$ by 50 years and in more than $60 \%$ by age 80 . Recently, Hjern et al reviewed 234 patients with CT-confirmed diverticulitis. The rate of severe diverticulitis observed with CT was lower in the younger patients $(2 \%$ versus $11.9 \%$; $P=0.025$ ). Surgical management during the first admission was similar in younger patients $(2 \%$ versus $6.8 \%$; $\mathrm{P}=0.271$ ); first episodes of acute diverticulitis being not more aggressive in younger patients [13]. Variables 'severity of disease' (Hinchey 1a (inflammation) versus $1 \mathrm{~b}$ (plus micro abscesses)) and 'participating and including hospital' were deemed most important with respect to outcome and therefore in need of stratification. Stratification for more than two variables is highly uncommon in randomized control trials.

Right-sided diverticulitis is excluded because of uncertainty about the underlying factors that contribute to right-sided diverticulitis. In literature, a clear distinction is made between left and right-sided diverticulitis. In Western countries, diverticulitis mostly affects the left colon and the incidence of right-sided diverticulitis is estimated to be below 4\%. However, in Asia and countries with a high Asian population, diverticular disease 
of the cecum and the ascending colon is a more widespread disease than the left-sided form of this disease. Sugihara et al reported on 615 Japanese patients with diverticular disease of the colon: $69.8 \%$ with right-sided and $15.9 \%$ with left-sided and $14.3 \%$ both-sided diverticular disease [44]. Left-sided diverticular disease is mainly based on pseudodiverticulae. The pathogenesis is based on a higher intraluminal pressure with consecutive hypertrophy of the colonic wall. In contrast, rightsided diverticulosis, typically is associated with normal intraluminal pressures and a tendency for bleeding rather than perforation, presumably owing to underlying connective tissue abnormality [45]. For the reason of uniformity of study population only left-sided diverticulitis will be included.

\section{Conclusion}

The DIABOLO trial is a multicenter randomized pragmatic trial (trialregister: NL29615.018.09, Clinicaltrial. gov: NCT01111253) comparing the cost-effectiveness of a conservative strategy (with admission and antibiotics) with a liberal treatment strategy (without antibiotics and no strict need for hospital admission) with respect to the primary endpoint time-to-full recovery.

\section{Acknowledgements}

The Netherlands Organization for Health Research and Development, Health Care Efficiency Research program, (ZonMw grant: 80-82310-97-10039) and the Dutch Digestive Diseases Foundation (MLDS grant: WO 08-54) funded the DIABOLO trial.

\section{Collaboration Group:}

Academisch Medisch Centrum, Amsterdam: Marja (MA) Boermeester (M.A. Boermeester@amc.uva.nl), Lidewine (L) Daniels (I.daniels@amc.uva.nl), Çağdaş (Ç) Ünlü (c.unlu@amc.uva.nl)

Kennemer Gasthuis, Haarlem, Hein (HBAC) Stockmann (stockmann@kg.nl), Niels (N) de Korte (ndekorte@yahoo.com), Johan (J. Ph.) Kuyvenhoven (kuyvenhoven@kg.nl)

Sint Lucas Andreas Ziekenhuis, Amsterdam: Bart (BC) Vrouenraets (bc vrouenraets@slaz.nl), Jurriaan (JB) Tuynman (j.tuynman@slaz.nl) Meander Medisch Centrum, Amersfoort: Esther (ECJ) Consten (ecj. consten@meandermc.nl), Bryan (BJM) van de Wall (bjm.vandewall@meandermc.nl), Ivo (IAMJ) Broeders (iamj. broeders@meandermc.nl) Vrije Universiteit Medisch Centrum, Amsterdam: Miquel (MA) Cuesta (ma. cuesta@vumc.nl), Marijn (MM) Poelman (mmarijn@hotmail.com) Onze Lieve Vrouwe Gasthuis, Amsterdam: Michael (MF) Gerhards (m.f. gerhards@olvg.nl), Koert (KFD) Kuhlmann, (k.f.d.kuhlmann@olvg.nl) Tergooi Ziekenhuizen, Hilversum / Blaricum: Anna (AAW) van Geloven, (avangeloven@tergooiziekenhuizen.nl)

Gelre Ziekenhuizen, Apeldoorn: Edwin (ES) van der Zaag (e.van.der. zaag@gelre.nl), Kemal Dogan (k.dogan@gelre.nl)

Albert Schweitzer Ziekenhuis, Dordrecht: Joost (JAB) van der Hoeven (j.a.b. vander.hoeven@asz.nl)

't Boven IJ Ziekenhuis, Amsterdam: Rutger (RJ) Klicks (r.klicks@bovenij.nl), Nik Dhar (n.dhar2@gmail.com)

Rode Kruis Ziekenhuis, Beverwijk: Huib (HA) Cense (hcense@rkz.nl), Gerrit (GH) de Groot (gdegroot@rkz.nl), Yuri Pikoulin (ypikoulin@rkz.nl) Máxima Medisch Centrum, Veldhoven: Rudi (RMH) Roumen (r.roumen@mmc. nl), Wilfred Truin (wilfredtruin@hotmail.com)

Spaarne Ziekenhuis, Hoofddorp: Quirijn (QAJ) Eijsbouts

(Qeijsbouts@spaarneziekenhuis.nl), Philip (PR) de Reuver, (P.R.deReuver@amc. uva.nl)
ZGT, Almelo/ Hengelo, lan (IF) Faneyte (i.faneyte@zgt.nl), Ad (ATPM) Claassen (a.claassen@zgt.nl), Susan Mollink (su.mollink@zgt.nl)

Amphia Ziekenhuis, Breda: Rogier (RMPH) Crolla (rcrolla@amphia.nl)

\section{Author details}

'Department of Surgery, Sint Lucas Andreas Hospital Amsterdam, the Netherlands. ${ }^{2}$ Department of Surgery, Academic Medical Center Amsterdam, the Netherlands. ${ }^{3}$ Department of Surgery, Kennemer Gasthuis, Haarlem, the Netherlands. ${ }^{4}$ Department of Surgery, Meander Medisch Centrum Amersfoort, the Netherlands. ${ }^{5}$ Department of Surgery, VU Medical Center Amsterdam, the Netherlands. ${ }^{6}$ Department of Surgery, Onze Lieve Vrouwe Gasthuis Amsterdam, the Netherlands. ${ }^{7}$ Department of Surgery, Tergooi Hospital Hilversum, the Netherlands. ${ }^{8}$ Department of Surgery, Gelre Hospital Apeldoorn, the Netherlands. ${ }^{9}$ Department of Surgery, Albert Schweitzer Hospital Dordrecht, the Netherlands. ${ }^{10}$ Department of Surgery, Boven IJ Hospital Amsterdam, the Netherlands. ${ }^{11}$ Department of Surgery, Rode Kruis Hospital Beverwijk, the Netherlands. ${ }^{12}$ Department of Surgery, Maxima Medisch Centrum Veldhoven, the Netherlands. ${ }^{13}$ Department of Surgery, Spaarne Hospital Hoofddorp, the Netherlands. ${ }^{14}$ Department of Surgery, Erasmus Medical Center Rotterdam, the Netherlands. ${ }^{15}$ Department of Gastroenterology, Academic Medical Center Amsterdam, the Netherlands.

${ }^{16}$ Department of Clinical Epidemiology and Biostatistics, Academic Medical Center Amsterdam, the Netherlands.

\section{Authors' contributions}

ÇÜ drafted the manuscript, and ÇÜ, NDK, RJB, BCV and MAB designed the study. All 3D diverticulitis collaboration participated in the definite design of the study during several meetings and critically revised the manuscript. All authors read and approved the final manuscript.

\section{Competing interests}

The authors declare that they have no competing interests.

Received: 30 May 2010 Accepted: 20 July 2010 Published: 20 July 2010

\section{References}

1. Parks TG: Natural history of diverticular disease of the colon: a review of 521 cases. BMJ 1969, 4:639-642.

2. Mendeloff Al: Thoughts on epidemiology of diverticular disease. Clin Gastroenterel 1986, 15:855-77.

3. Sarin S, Boulos PB: Long-term outcome of patients presenting with acute complications of diverticular disease. Ann R Coll Surg Engl 1994, 76:117-120.

4. Painter NS, Burkitt DP: Diverticular disease of the colon:a deficiency disease of Western civilization. Br Med J 1971, 2:450-454.

5. Aldoori WH, Giovannucci EL, Rimm EB, Wing AL, Trichopoulos DV, Willett WC: A prospective study of alcohol, smoking, caffeine, and the risk of symptomatic diverticular disease in men. Ann Epidemiol 1995, 5:221-228

6. Aldoori WH, Giovannucci EL, Rimm EB, Wing AL, Willett WC: Use of acetaminophen and nonsteroidal anti-inflammatory drugs: a prospective study and the risk of symptomatic diverticular disease in men. Arch Fam Med 1998, 7:255-260.

7. Tursi A, Brandimarte G, Elisei W, Giorgetti GM, Inchingolo CD, Aiello F: Faecal calprotectin in colonic diverticular disease; a case-control study. Int J Colorectal Dis 2009, 24:49-55.

8. Mueller MH, Glatzle J, Kasparek MS, Becker HD, Jehle EC, Zittel TT, Kreis ME: Long-term outcome of conservative treatment in patients with diverticulitis of the sigmoid colon. Eur J Gastroenterol Hep 2005, 17:649-654.

9. Lameris W, van Randen A, Bipat S, Bossuyt PM, Boermeester MA, Stoker J: Meta-analysis of accuracy of CT and US in diverticulitis. Eur Radiol 2008, 18(11):2498-511.

10. Kaiser AM, Jiang JK, Lake JP, Ault G, Artinyan A, Gonzalez-Ruiz C, Essani R, Beart RW Jr: The managment of complicated diverticulitis and the role of computed tomography. Am J Gastroenter 2005, 100:910-917.

11. Wasvary $H$, Turfah F, Kadro O, Beauregard W: Same hospitalization resection for acute diverticulitis. Am Surg 199 65(7):632-5.

12. Ambrosetti P, Grossholz M, Becker C, Terrier F, Morel P: Computed tomography in acute left colonic diverticulitis. Br J Surg 1997, 84:532-534. 
13. Shaikh $\mathrm{S}$, Krukowski $\mathrm{ZH}$ : Outcome of a conservative policy for managing acute sigmoid diverticulitis. Br J Surg 2007, 94:876-9.

14. Hjern F, Josephson T, Altman D, Holmström B, Johansson C: Outcome of younger patients with acute diverticulitis. Br J Surg 2008, 95:758-764.

15. Jacobs DO: Diverticulitis. N Engl J Med 2007, 357:2057-66.

16. Brook I, Farzier EH: Aerobic and anaerobic microbiology in intraabdominal infections associated with diverticulitis. Clinical Microbiology 2000, 49:827-830.

17. Kellum JM, Sugerman HJ, Coppa GF, Way LR, Fine R, Herz B, Speck EL, Jackson D, Duma RJ: Randomized, prospective comparison of cefoxitin and gentamicin-clindamycin in the treatment of acute colonic diverticulitis. Clin Ther 1992, 14(3):376-384.

18. Fink M, Smith LE, Rosenthal D: Antibiotic choice in the nonoperative management of acute divertiulitis coli. Am Surg 1981, 47(5):201-203.

19. Ridgway P, Latif A, Shabbir J, Ofriokuma F, Hurley MJ, Evoy D, O'Mahony JB, Mealy K: Randomised Controlled Trial of Oral versus Intravenous Therapy for Clinically Diagnosed Acute Uncomplicated Diverticulitis. Colorectal Dis 2009, 11(9):941-6.

20. Hjern F, Josephson T, Altman D, Holmström B, Mellgren A, Pollack J, Johansson C: Conservative treatment of acute colonic diverticulitis: are antibiotics always mandatory? Scan J Gastro 2007, 42:41-4

21. Van de Linde MJ, Wikkeling M, Driessen WM, Croiset van Uchelen FA, Roumen RM: Is er een rol voor antibiotica bij de conservatieve behandeling van acute diverticulitis coli? Ned Tijdschr Heelk 1996, 5:194-7.

22. Munikrishnan V, Helmy A, Elkhider H, Omer AA: Management of acute diverticulitis in the East Anglian region: results of a United Kingdom regional survey. Dis Colon Rectum 2006, 49(9):1332-40.

23. Stollman $\mathrm{NH}$, Raskin JB: Diagnosis and management of diverticular disease of the colon in adults. Ad Hoc Practise Parameters Committee of the American College of Gastroenterology. Am J Gastroenterol 1999, 94(11):3110-21.

24. Rafferty J, Shellito P, Hyman NH, Buie WD: Standard committee of American Society of Colon and Rectal Surgeons. Dis Colon Rectum 2006, 49(7):939-44.

25. Kohler L, Sauerland S, Neugebauer E: Diagnosis and treatment of diverticular disease: Results of a consensus development conference. The scientific committee of the European association for endoscopic surgery. Surg Endosc 1999, 13(4):430-6.

26. Surgical treatment of diverticulitis. Patient care committee of the Society of Surgery of the Alimentary Tract (SSAT). J Gastrointest Surg 1999, 3(2):212-3

27. World Gastroenterology Organisation. [http://www.worldgastroenterology. org].

28. Stichting Werkgroep AntibioticaBeleid. [http://customid.duhs.duke.edu/NL/ Main/Diagnosis.asp?Diagnosis|D=339].

29. Johannes CB, Ziyadeh N, Seeger JD, Tucker E, Reiter C, Faich G: Incidence of allergic reactions associated with antibacterial use in a large, managed care organization. Drug Safety 2007, 30(8):705-713.

30. Guideline Summary. [http://www.guideline.gov/summary/summary.aspx? doc_id=10783].

31. Bone RC, Balk RA, Cerra FB, Dellinger RP, Fein AM, Knaus WA, Schein RM, Sibbald WJ, ACCP/SCCM Consensus Conference Committee: Definitions for sepsis and organ failure and guidelines for the use of innovative therapies in sepsis. The ACCP/SCCM Consensus Conference Committee. American College of Chest Physicians/Society of Critical Care Medicine. Chest 2009, 136(5 Suppl):e28.

32. Loffeld RJ, van der Putten AB: Diverticular disease of the colon and concomitant abnormalities in patients undergoing endoscopic evaluation of the large bowel. Colorectal Dis 2002, 4(3):189-192.

33. Sandler RS, Everhart JE, Donowitz M, Adams E, Cronin K, Goodman C, Gemmen E, Shah S, Avdic A, Rubin R: The burden of selected digestive diseases in the United States. Gastroenterology 2002, 122:1500-11.

34. Etzioni DA, Mack TM, Beart RW, Kaiser AM Jr: Diverticulitis in the United States: 1998-2005 Changing Patterns of Disease and Treatment. Ann Surg 2009, 249(2):210-217.

35. Ahovuo-Saloranta A, Borisenko OV, Kovanen N, Varonen H, Rautakorpi UM, Williams JW Jr, Mäkelä M: Antibiotics for acute maxillary sinusitis. Cochrane Database of Systematic Reviews 2008, 2:CD000243.

36. Vouloumanou EK, Karageorgopoulos DE, Kazantzi MS, Kapaskelis AM, Falagas ME: Antibiotics versus placebo or waithfull watching for acute otitis media: A meta-analysis of randomised controlled trials. J Antimicrob Chemother 2009, 64:116-24.

37. Goossens H: Antibiotic consumption and link to resistance. Clin Microbiol Infect 2009, 15(Suppl 3):12-15.

38. Nelson R: Antibiotic treatment for Clostridium difficile-associated diarrhea in adults. Cochrane Database of Systematic Reviews 2007, 3 CD004610.

39. Di Mario F, Aragona G, Leandro G, Comparato G, Fanigliulo L, Cavallaro LG, Cavestro GM, lori V, Maino M, Moussa AM, Gnocchi A, Mazzocchi G, Franzé $A$ : Efficacy of mesalazine in the treatment of symptomatic diverticular disease. Dig Dis Sci 2005, 50(3):581-6.

40. Latella G, Pimpo MT, Sottili S, Zippi M, Viscido A, Chiaramonte M, Frieri G: Rifaximin improves symptoms of acquired uncomplicated diverticular disease of the colon. Int J Colorectal Dis 2003, 18(1):55-62.

41. Tursi A, Brandimarte G, Daffina R: Long-term treatment with mesalazine and rifaximin versus rifaximin alone for patients with recurrent attacks of acute diverticulitis of colon. Dig Liver Dis 2002, 34(7):510-5.

42. Tursi A, Brandimarte G, Giorgetti GM, Elisei W: Continuous versus cyclic mesalazine therapy for patients affected by recurrent symptomatic uncomplicated diverticular disease of the colon. Dig Dis Sci 2007, 52(3):671-4.

43. Mizuki A, Nagata H, Tatemichi M, Kaneda S, Tsukada N, Ishii H, Hibi T: The out-patient management of patients with acute mild-to-moderate colonic diverticulitis. Aliment Pharmacol Ther 2005, 21(7):889-97.

44. Sugihara K, Muto T, Morioko Y, Asano A, Yamamoto T: Diverticular disease of the colon in Japan. A review of 615 cases. Dis Colon Rectum 1984, 27(8):531-7.

45. Strate LL: Lower GI bleeding: epidemiology and diagnosis. Gastroenterology Clinics of North America 2005, 34(4):643-664.

\section{Pre-publication history}

The pre-publication history for this paper can be accessed here: http://www.biomedcentral.com/1471-2482/10/23/prepub

doi:10.1186/1471-2482-10-23

Cite this article as: Ünlü et al.: A multicenter randomized clinical trial investigating the cost-effectiveness of treatment strategies with or without antibiotics for uncomplicated acute diverticulitis (DIABOLO trial). BMC Surgery 2010 10:23.

\section{Submit your next manuscript to BioMed Central and take full advantage of:}

- Convenient online submission

- Thorough peer review

- No space constraints or color figure charges

- Immediate publication on acceptance

- Inclusion in PubMed, CAS, Scopus and Google Scholar

- Research which is freely available for redistribution

Submit your manuscript at www.biomedcentral.com/submit
Biomed Central 